African Crop Science Journal by African Crop Science Society is licensed under a Creative Commons Attribution 3.0 Uganda License. Based on a work at www.ajol.info/ and www.bioline.org.br/cs DOI: https://dx.doi.org/10.4314/acsj.v27i3.6

\title{
GGE BIPLOT ANALYSIS OF YIELD STABI LITY FOR ANDEAN DRY BEAN ACCESSIONS GROWN UNDER DIFFERENT ABIOTIC STRESS REGIMES IN TANZANIA
}

\author{
E.J. MNDOLWA, S.N. MSOLLA ${ }^{1}$, T.G. PORCH ${ }^{2}$ and P.N. MIKLAS ${ }^{3}$ \\ Department of Crop and Soil Sciences, Washington State University, Prosser WA., USA \\ ${ }^{1}$ Department of Crop Science, Sokoine University of Agriculture, Morogoro, Tanzania \\ ${ }^{2}$ United States Department of Agriculture - Agricultural Research Service - Mayaguez, PR., , USA \\ ${ }^{3}$ United States Department of Agriculture - Agricultural Research Service - Prosser, WA, USA \\ Corresponding author: phil.miklas@ars.usda.gov
}

(Received 27 September 2018; accepted 5 August 2019)

\begin{abstract}
Large seeded Andean dry beans (Phaseolus vulgaris L.) are most preferred in Africa. However, low soil fertility and increasing drought stress conditions due to climate change are among the challenges faced by farmers in this region. The purpose of this study was to identify Andean genotypes with yield stability and to identify the best environments for selection of this trait. GGE-Biplot analysis was used to examine 183 Andean bean genotypes in Tanzania. Results indicated significant environment (E), genotype $(\mathrm{G})$ and genotype $\mathrm{x}$ environment (GE) effects for seed yield. The environment explained $46 \%$, genotype $20 \%$, and GE $34 \%$ of the total $(\mathrm{G}+\mathrm{E}+\mathrm{GE})$ variation. Two principal components explained $41.21 \%$ (PC1) and 26.35\% (PC2) of GGE sum of squares. The Andean genotypes, ADP-102 (Jessica)- purple mottle, large seed, bush plant habit, released by Selian Agriculture Research Institution (ARI) in Tanzania; ADP-220 (G5625)- red, large seed, vine plant habit, from Central America; ADP-276 (G13654) - brown, medium seed, vine, from Mexico; and ADP-648 ('Red Kloud') large red kidney, with bush plant habit, were stable across environments and can be recommended for general adaptation across environments. An individual location for selection for yield stability was not identified, thus justifying the continued need for multiple test sites.
\end{abstract}

Key Words: Drought stress, low soil fertility stress, Phaseolus vulgaris, yield stability

\section{RÉSUMÉ}

Les haricots secs andins à grosses graines (Phaseolus vulgaris L.) sont les plus préférés en Afrique. Cependant, la faible fertilité du sol et le stress croissant de la sécheresse causé par le changement climatique font partie des défis auxquels sont confrontés les agriculteurs de cette région. L'objectif de cette étude était d'identifier les génotypes andins avec une stabilité de rendement et d'identifier les meilleurs environnements pour la sélection de ce trait. L'analyse GGE-Biplot a été utilisée pour examiner 
183 génotypes de haricot andin en Tanzanie. Les résultats ont montré des effets significatifs sur l'environnement (E), le génotype (G) et le génotype x environnement (GE) sur le rendement en grain. L'environnement expliquait $46 \%$, le génotype $20 \%$ et l'EG $34 \%$ de la variation totale $(\mathrm{G}+\mathrm{E}+\mathrm{GE})$. Deux composantes principales expliquent $41,21 \%$ (PC1) et $26,35 \%$ (PC2) de la somme des carrés GGE. Les génotypes andins, ADP-102 (Jessica) - marron violet, grosse graine, habitude de plante de brousse, publiés par l'Institut de recherche sur l'agriculture Selian (ARI) en Tanzanie; ADP-220 (G5625) Rouge, grosse graine, habitude de plante de la vigne, d'Amérique centrale; ADP-276 (G13654) - brun, graine moyenne, vigne, en provenance du Mexique; et le grand rein rouge ADP-648 («Red Kloud»),

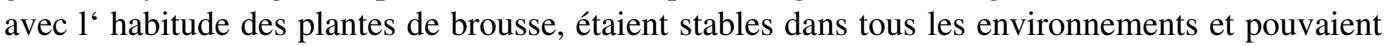
être recommandés pour une adaptation générale dans tous les environnements. Un emplacement individuel pour la sélection de la stabilité du rendement n'a pas été identifié, ce qui justifie le besoin de la continuite de test multiples des sites.

Mots Clés: Stress de sécheresse, stress lié à la faible fertilité du sol, Phaseolus vulgaris, stabilité du rendement

\section{INTRODUCTION}

Dry bean (Phaseolus vulgaris L.) productivity is highly influenced by climatic conditions and deviations from the optimal conditions (Vandemark et al., 2014). Bean productivity becomes even more limited under stressful environmental conditions caused by low fertility or periodic drought. Dry bean cultivars with tolerance to these stresses will be needed for sustainable bean production (Ghassemi et al., 1995; Pessarakli and Szabolcs, 1999). Progress to improve yield of common bean under low fertility or drought stress has been slow compared to research conducted to improve common bean for various agronomic traits (Kelly et al., 1998).

The larger-seeded dry beans of Andean origin are preferred in Africa (Wortmann et al., 1995). These beans are even less stress tolerant and less broadly adapted to different environments, compared to dry bean of Middle American origin (Singh, 1999; Beebe et al., 2013). Contributing reasons can be the narrower genetic diversity (Beebe et al., 2001) and determinate bush growth habit prominent in Andean beans. Determinacy usually results in more synchronised and shorter flowering duration, which results in reduced potential to recover from stressful events. Andean beans with vine growth habits exist primarily as landraces, which are less adapted to warmer lowland environments (Beebe et al., 2001). Therefore, it is important to study the performance of different Andean genotypes with different growth habits across different environments to help select the best genotypes for target regions.

The study of Genotype $x$ Environment (GE) interaction is important because soil fertility and climate change are global concerns. Basically, GE interaction occurs when genotypes respond differently in different environments. It is well known that significant GE influences the selection of genotypes for either broad adaptation across environments, or narrow adaptation for specific environments. A significant GE interaction indicates that the genotype effect depends on the environment and each genotype responds to environmental variation differently (Julius et al., 2015). The purpose of this study was to use GGE to better understand the $G$ and GE effects of different environments for selection of Andean dry bean for improved yield stability.

\section{MATERIALS AND METHODS}

A panel of 183 dry bean accessions, representing bush and vine growth habit types were tested across three sites in Tanzania, for two years. The panel comprised of East African landraces, local checks, cultivars and advanced 
breeding lines representative of the global genetic diversity for Andean beans grown in Africa and the Americas. These accessions represent a subset of the Andean Diversity Panel (ADP) described by Cichy et al. (2015). A description of individual accessions in the ADP can be found at http://arsftfbean.uprm. edu/bean/?page_id=941.

Experimental sites. The field trials were conducted in three distinct regions of Tanzania, namely Arusha, Morogoro and Mbeya. The dry bean breeding programme based at the Sokoine University of Agriculture in Morogoro, Tanzania is located at $6^{\circ} 49.26122 \mathrm{~S} /$ $37^{\circ} 39.67322 \mathrm{E}$, at altitude 526 meters above the sea level (masl). The soils are reddish brown, well-drained fine clay Ultisol. The area receives bimodal rainfall with lower precipitation (November to January) and higher precipitation (March to May) periods. Generally, low fertility soils is a common problem due to lack of fertiliser use. But recently rainfall has become unreliable, thus accentuating the effect of heat and terminal drought stress in the Morogoro region. Bean production is sparse in this area, compared to the Arusha, Kigoma, and Southern Highland (Mbeya) regions, where most of the bean production occurs. Nonetheless, the SUA research farm is a prominent environment used to evaluate and select dry bean breeding lines for production across Tanzania.

The other test environments used by the SUA bean breeding programme include the
Selian Research Station in Arusha region, which is located at $3^{\circ} 22.00022 \mathrm{~S} /$ $36^{\circ} 40.99982 \mathrm{E}$, at an elevation of 1387 masl. The soil type is a volcanic ash Nitisol. Like Morogoro, the site receives bimodal rainfall with lower precipitation (November to January) and higher precipitation (March to May) periods.

The Uyole Research Station near Mbeya in the Southern Highlands is located at $8^{\circ} 542003$ $\mathrm{S} / 33^{\circ} 272003 \mathrm{E}$. The altitude at the site ranges from 1750 - 1850 masl. Uyole has a welldrained heavy soil which tends toward acidic with low to medium levels of soil nutrients. The area is characterised by unimodal rainfall starting from October/November and ending in April/May. Uyole and Selian Stations have separate national dry bean breeding programs that target cultivar development for their specific regions. The experiments conducted at these sites received rainfall only (precipitation not reported) as no supplemental irrigation was provided.

Experimental design. The experimental design was a randomised complete block, with two replications. Single row plots of $8 \mathrm{~m}$ length and with 40 plants per row with interrow spacing of $50 \mathrm{~cm}$ were used.

Data collection and statistical analysis. From each site, soil samples were taken prior to planting, to check for the nutrient status of the fields (Table 1). For GGE stability analysis, only seed yield $\left(\mathrm{kg} \mathrm{ha}^{-1}\right)$ data were used. Seed

TABLE 1. Soil mineral $\mathrm{N}$ and available $\mathrm{P}$ status for five Tanzania field test environments used to screen a subset of 183 genotypes from the Andean Diversity Panel for yield performance

\begin{tabular}{lccccc}
\hline Site & Year & Environment & $\begin{array}{c}\text { Number of } \\
\text { genotypes }\end{array}$ & $\begin{array}{c}\text { Soil N }=\mathrm{NO}_{3}-\mathrm{N}+ \\
\mathrm{NH}_{4}-\mathrm{N}\left(\mathrm{kg} \mathrm{N} \mathrm{ha}^{-1}\right)\end{array}$ & $\begin{array}{r}\text { Bray P 1 } \\
\left(\mathrm{mg} \mathrm{kg}^{-1}\right)\end{array}$ \\
\hline Mbeya & 2013 & Env 1 & 183 & 49 & 7 \\
Morogoro & 2013 & Env 2 & 183 & 53 & 2 \\
Morogoro & 2014 & Env 3 & 183 & 49 & 10 \\
Mbeya & 2014 & Env 4 & 183 & 67 & 5 \\
Arusha & 2014 & Env 5 & 183 & 71 & 21 \\
\hline
\end{tabular}


yield was estimated from a row per plot harvested.

A combined analysis across the five environments, abbreviated as Env 1, Env 2, Env 3, Env 4 and Env 5 representing Mbeya 2013, Morogoro 2013, Morogoro 2014, Mbeya 2014 and Arusha 2014, respectively, for 183 genotypes was performed using the PROC GLM procedure in SAS version 9.4 (SAS Institute, Cary, NC, 2011). During the test of hypotheses for mixed model analysis of variance, environments and replications were treated as random variables; whereas genotypes were treated as a fixed variable. A single location with different years (growing seasons) were treated as different environments (E), because field conditions and weather varied each year. Partitioning of variances into different sources to test the effects of G, E and GE interactions was performed.

Genotype main effect. To perform GGE biplot analysis, least square means from each environment were analysed using the GGE BiplotGUI package from the statistical software R (Yan and Tinker, 2006). A generalised linear model was used to determine the variation in yield among $\mathrm{E}, \mathrm{G}$ and $\mathrm{GE}$. The GGE biplots show the first two principal components ( $\mathrm{PC} 1$ and $\mathrm{PC} 2$ ), where axis 1 is for $\mathrm{PC} 1$ and axis 2 is for $\mathrm{PC} 2$.

Heritability estimates. Narrow sense heritability for yield across environments was estimated, using the variance components; which included genotypic $(G)$ variance, environmental (E) variance and genotype $\mathrm{x}$ environment (GE) variance across environments generated using the PROC GLM procedure in SAS. The calculation was done using the mean squares from the ANOVA Table 2 as described by Hallauer et al. (2010):

$$
\mathrm{h}^{2}=\frac{\delta^{2}{ }_{G}}{\left[\delta^{2}{ }_{G}+\frac{\delta^{2}{ }_{G X E}}{e}+\frac{\delta^{2}{ }_{E}}{r e}\right]}
$$

Where:

$\delta^{2}{ }_{G} \quad=$ genotypic variance;

$\delta_{G X E}^{2}=$ genotypic by environment variance;

$\delta^{2} \quad=$ error variance; and

$\mathrm{r} \quad=$ number of replications

\section{RESULTS AND DISCUSSION}

There was significant variation $(\mathrm{P}<0.005)$ for all three sources of variation (E, G and GE) for seed yield (Table 2). Variation among genotypes evaluated in different environments could be explained by the fact that the genotypes were genetically diverse. Therefore, when genetic variation is high, there is greater potential for genetic gains through breeding and selection (Kelly et al., 1998). When variation due to GE is high, then the genotypes are responding differently for yield in the different environments. In this case, closer inspection of the genotype ranking for yield

TABLE 2. Mean squares from analysis of variance for 183 Andean bean genotypes evaluated in five different environments in Tanzania

\begin{tabular}{llrrr}
\hline Traits & Source & DF & Mean square & Pr $>$ F \\
\hline \multirow{2}{*}{ Tanzania } & Environment (Env) & 4 & 38364618 & $<.0001$ \\
& Genotype & 182 & 209813 & $<.0001$ \\
& Env x genotype & 728 & 139993 & $<.0001$ \\
\hline
\end{tabular}


across environments is needed to identify stable yielding genotypes.

Mean seed yields are presented in Table 3. The highest mean seed yield (1382 $\left.\mathrm{kg} \mathrm{ha}^{-1}\right)$ was recorded in Mbeya 2014 (Env 4); while the minimum yield $\left(499 \mathrm{~kg} \mathrm{ha}^{-1}\right)$ was recorded in Morogoro 2013 (Env 2). Seed yield for Mbeya 2013 (Env1), Morogoro 2014 (Env 3) and Arusha 2014 (Env 5) did not differ significantly. The five environments could be ranked in terms of their grain yield potential as follows: Mbeya 2014 > Arusha $2014>$ Morogoro $2014>$ Mbeya $2013>$ Morogoro 2013. The percentage sum of squares for $E$, G, and GE was 46, 20 and 34\%, respectively (Table 4). Van Eeuwijk et al. (1995); Beyene et al. (2011) and Sserumaga et al. (2015), in studies of maize, reported higher genotypic variation in grain yield than the effect of GE interaction for yield. Similar results were reported by Hoyos-Villegas et al. (2016), who examined the performance and adaptability of Mesoamerican common bean genotypes under irrigation versus rain-fed conditions in Michigan. However, in the present study, E was higher than GE and G, suggesting that the environmental conditions differed. According to soil test results (Table 1), there was wide variability in soil fertility levels between test sites. This variability in soil fertility may have contributed to the variation in yield observed across the five environments, as well.

TABLE 3. Seed yield for 183 Andean bean genotypes evaluated in five environments in Tanzania

\begin{tabular}{llc}
\hline Environments & Location & $\begin{array}{c}\text { Mean seed } \\
\text { yield }\left(\mathrm{kg} \mathrm{ha}^{-1}\right) \dagger\end{array}$ \\
\hline Environment 1 & Mbeya 2013 & $778.5^{\mathrm{b}}$ \\
Environment 2 & Morogoro 2013 & $499.4^{\mathrm{c}}$ \\
Environment 3 & Morogoro 2014 & $783.0^{\mathrm{b}}$ \\
Environment 4 & Mbeya 2014 & $1382.0^{\mathrm{a}}$ \\
Environment 5 & Arusha 2014 & $789.4^{\mathrm{b}}$ \\
\hline
\end{tabular}

$\dagger$ Means followed by the same letter within the same column are not significantly different $(\mathrm{P}=0.05)$

Tukey comparisons of mean

TABLE 4. Effect of E, G and GE from total $\mathrm{SS}_{(\mathrm{G})}, \mathrm{SS}_{(\mathrm{E})}$ and $\mathrm{SS}_{(\mathrm{GE})}$ and heritability estimates for 183 common bean genotypes evaluated in five different environments in Tanzania

\begin{tabular}{lc}
\hline Source of variation & Tanzania (\%) \\
\hline Environment & 46 \\
Genotypic & 20 \\
Gen x Env & 34 \\
CV & 28 \\
Heritability & 26 \\
\hline
\end{tabular}


Abiotic stress tolerance measured by seed yield is a heritable trait in common bean and other crops (Clark and Duncan, 1991). In this study, heritability was low $26 \%$ indicating that seed yield was highly influenced by the environment (Table 4).

Biplot analysis. The significant GE interactions for yield observed in the present study indicated that these data were suitable for GGE Biplot analysis. To visualise the yields from genotypes and interactions between genotypes and environment, biplots were generated based on a table, "Tester-centered
(G+GE)" without scaling in row metric preserving (JK biplot) in R. Several biplots were generated to examine the relationships among $\mathrm{G}$ and GE, as described in Yan and Tinker (2006).

From the GGE biplot analysis, the first principal component captured $41.21 \%$ of the total sum of squares for $\mathrm{G}$ and GE; and the second principal component captured $26.35 \%$.

Figure 1 was used to visualise relationships between test environments. The angle formed when two environmental axes meet explains if there is a correlation between the two environments. An acute angle $>90^{\circ}$ indicates

Biplot analysis



Figure 1. Relation among five environments in a genotype $\mathrm{x}$ environment (GE) interaction study for yield performance of Andean dry bean in Tanzania. 
positive correlation, an obtuse angle $<90^{\circ}$ indicates a negative correlation and a right angle $\left(=90^{\circ}\right)$ indicates no correlation (Yan and Tinker, 2006). Our results (Fig. 1) indicate a negative correlation between Morogoro 2013 and Arusha 2014, no correlation between Mbeya 2013 and Arusha 2014, and all other environments are positively correlated. A shorter distance between environments indicates similarity for discriminating genotypes, this is determined by the angle between the environment and the length of their vectors. Thus, Mbeya 2013, Morogoro 2013 and Morogoro 2014 are similar and fall in one group; while Mbeya 2014 and Arusha 2014 are similar and fall in another group. The positive correlations among environments indicate that fewer test environments can be used to discriminate yield performance of the genotypes.

The length of environment vectors gives information about the discriminating ability of the environments (Yan and Tinker, 2006). From Figure 2, Morogoro 2013 and Mbeya 2014 are

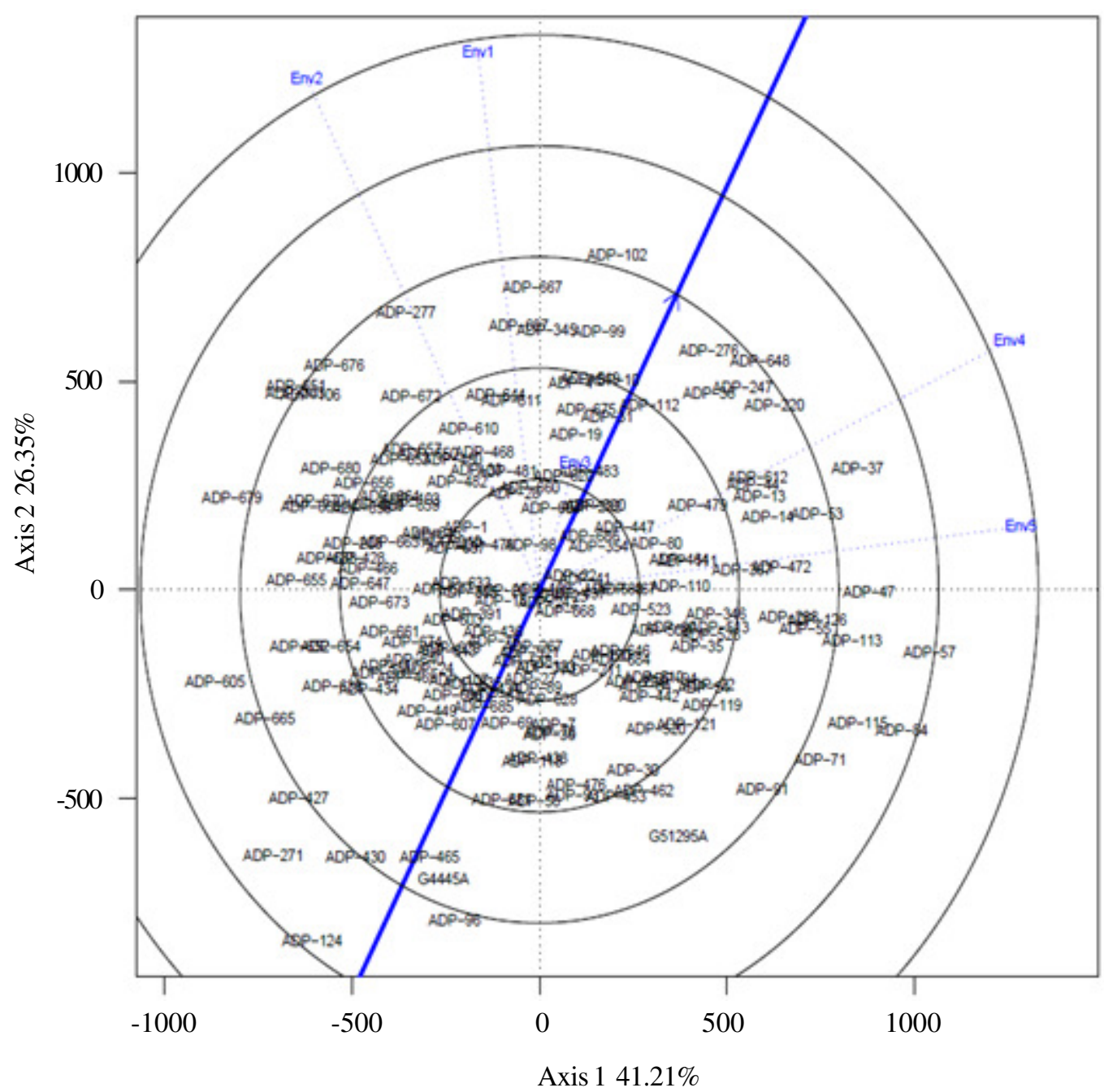

Figure 2. Discriminativeness vs representativeness in a genotype $\mathrm{x}$ environment (GE) interaction study for yield performance of Andean dry bean in Tanzania. A description of ADP accessions is available at http://arsftfbean.uprm.edu/bean/?page $\mathrm{id}=941$. 
the most discriminating; while Morogoro 2014 is the least discriminating environment. Less discriminating environments give less information on genotypic performance, and thus should be eliminated as a test environment. The ideal environment should be located at or close to the environment axis with an arrow. An environment with a smaller angle to environmental axis is more representative. In this case, Morogoro 2014 was the most representative, but was the least discriminating, so has little value. Morogoro 2013 and Arusha 2014 are the least representative. The most discriminating, but least representative environments (Morogoro 2013 and Arusha 2014) can be used to select genotypes adapted to these specific environments. The most discriminating and most representative environments (Mbeya 2013 and Mbeya 2014) can be used to select genotypes with wider adaptation.

The ideal environment for selecting genotypes for general adaptation should be located at the centre of concentric circles (Fig. $3)$. This is the most informative and most discriminating environment. None of the five

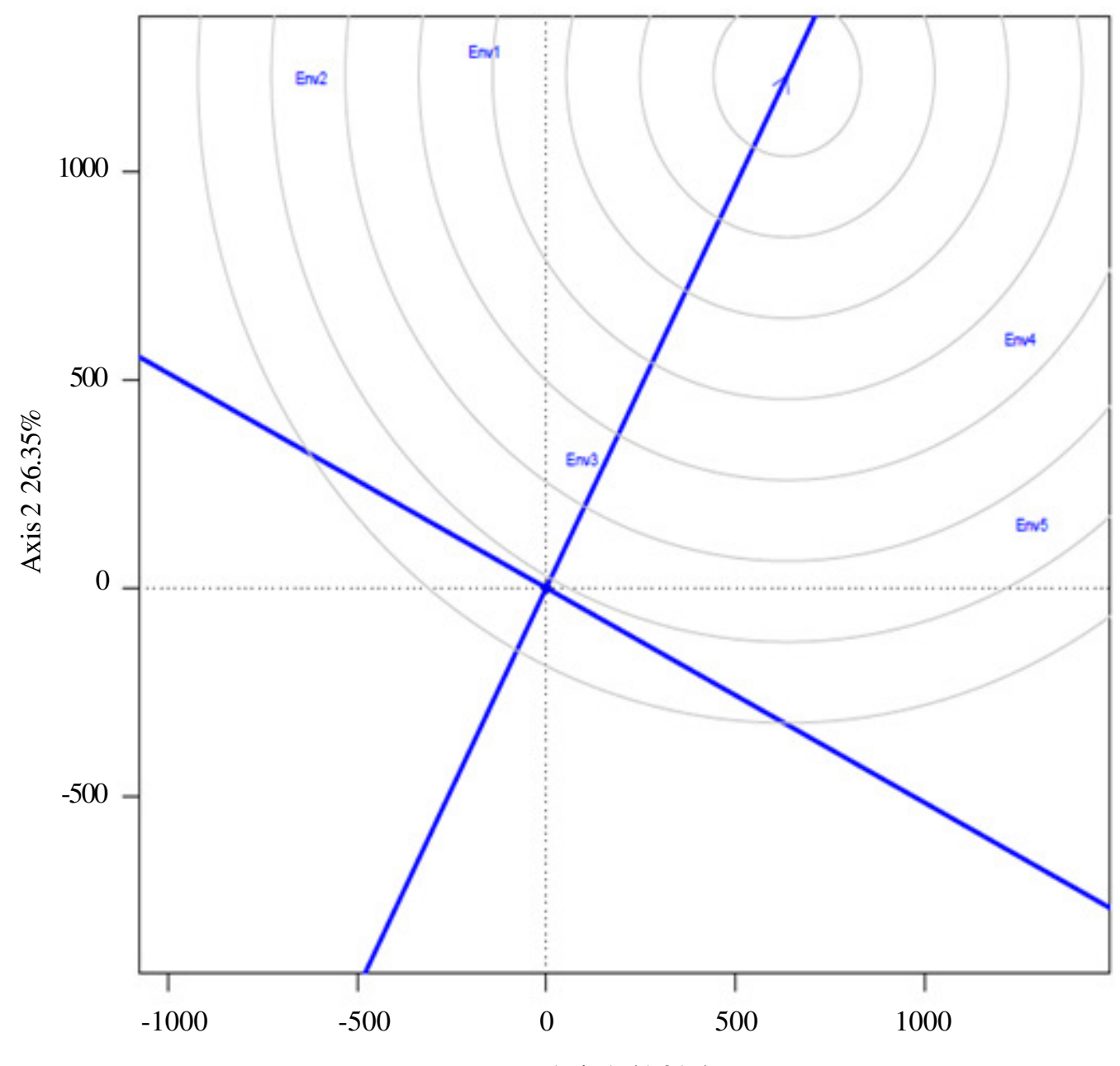

Axis $141.21 \%$

Figure 3. Ranking of the environments relative to the ideal environment for Andean dry bean yield performance in Tanzania. 
environments tested, fell within or even near the circle. Therefore, all environments are suitable for selecting genotypes for specific adaptation but not for general adaptation.

Results to identify the best genotype in each environment are presented in Figure 4 (whichwon-where). All genotypes located at the vertices in each sector of a polygon are the best for the environment in the sector where the vertices are located (Yan et al., 2000; Yan and Tinker, 2006; Frutos et al., 2013; Makumbi et al., 2015). ADP-102 is the best in Mbeya 2013 and Morogoro 2014, ADP-277 is the best in Morogoro 2013, ADP-648 is the best in Mbeya 2014; whereas ADP-37, ADP57 and ADP-84 are the best in Arusha 2014. The worst genotypes (low yield) are located at the vertices of the sectors in the polygon with no environments; thus, ADP-676, ADP651, ADP-679, ADP-605, ADP-271, ADP-124.

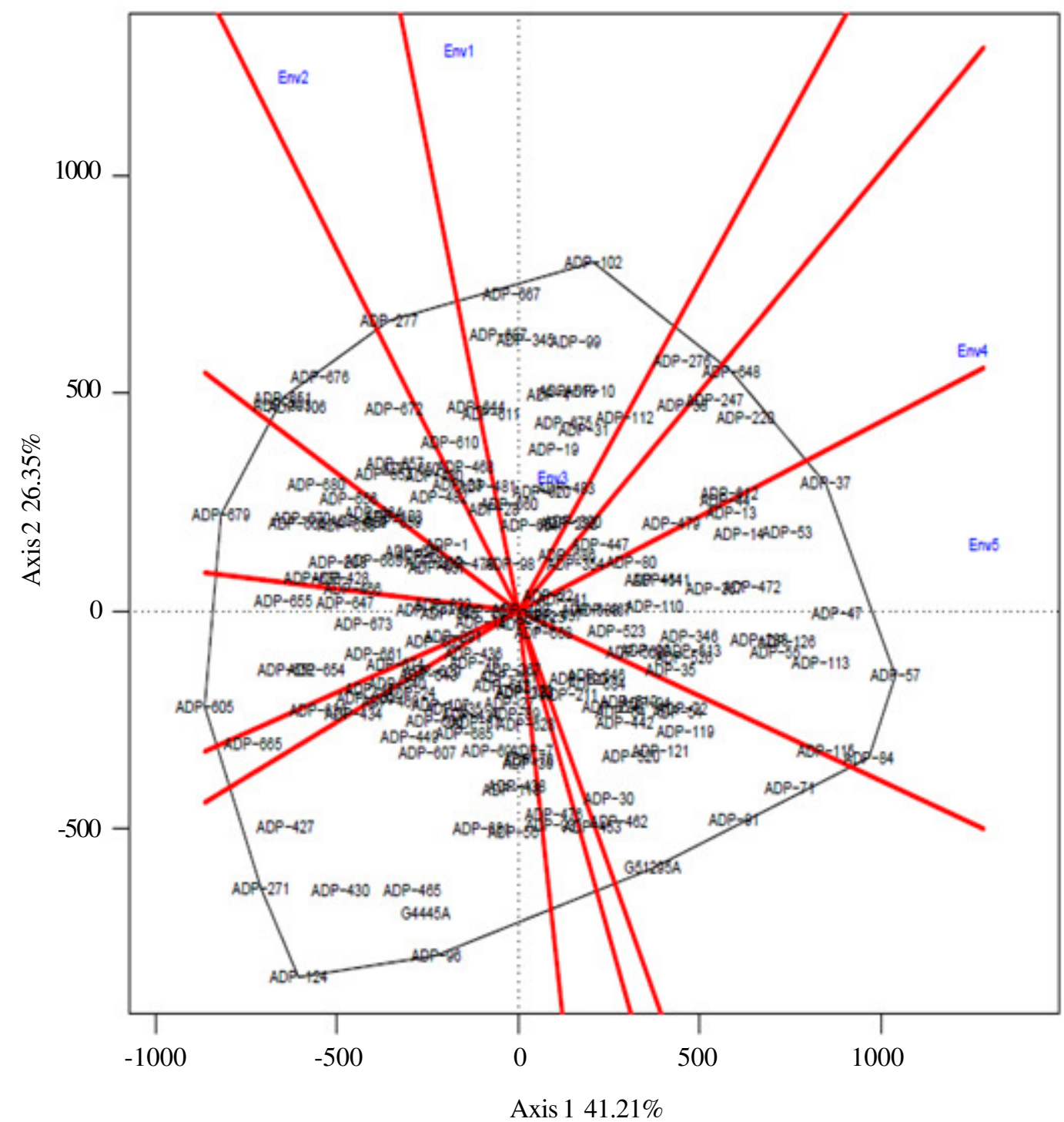

Figure 4. Identification of the best Andean dry bean genotypes for yield in five different environments (which-won-where) in Tanzania. 
ADP-96, G51295A, ADP-91 and ADP-71 are the worst genotypes (Fig. 4).

The average environmental axis (an axis with an arrow) is pointing to higher mean yield across environments (Fig. 5). Therefore, ADP-102 had the highest mean seed yield, followed by ADP-648, ADP-276 then ADP220. However, ADP-124 had the lowest mean seed yield.
The line perpendicular to the average environmental axis points to greater variability in either direction (poorer stability). Thus, ADP-57 and ADP-84 were highly unstable; while ADP-112 was highly stable. A genotype can be very unstable if it has higher above average yield in one environment and below average yield in another environment. Moreover, a genotype can be highly stable,

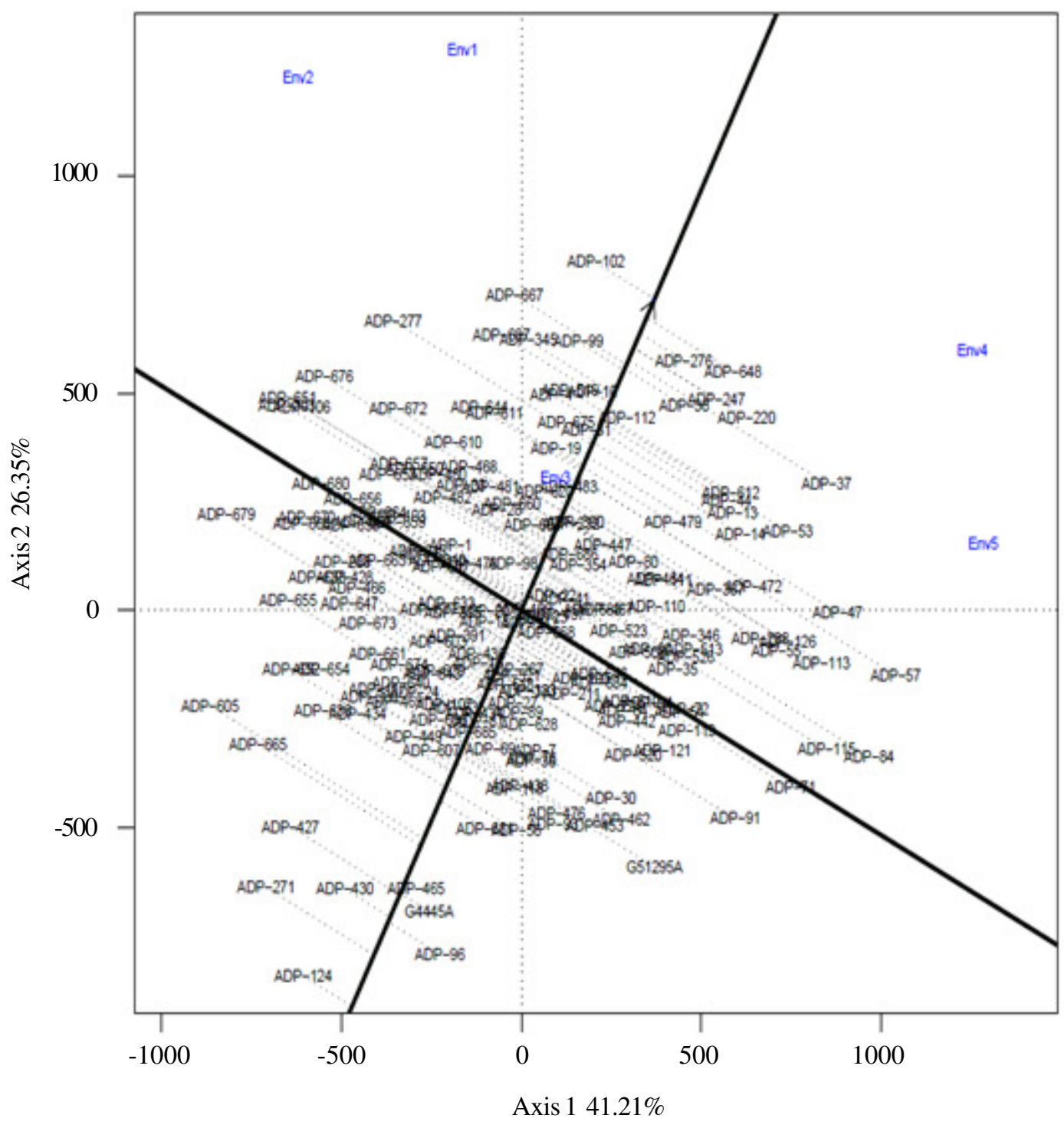

Figure 5. Mean seed yield and Andean dry bean genotype stability across five environments in Tanzania. 


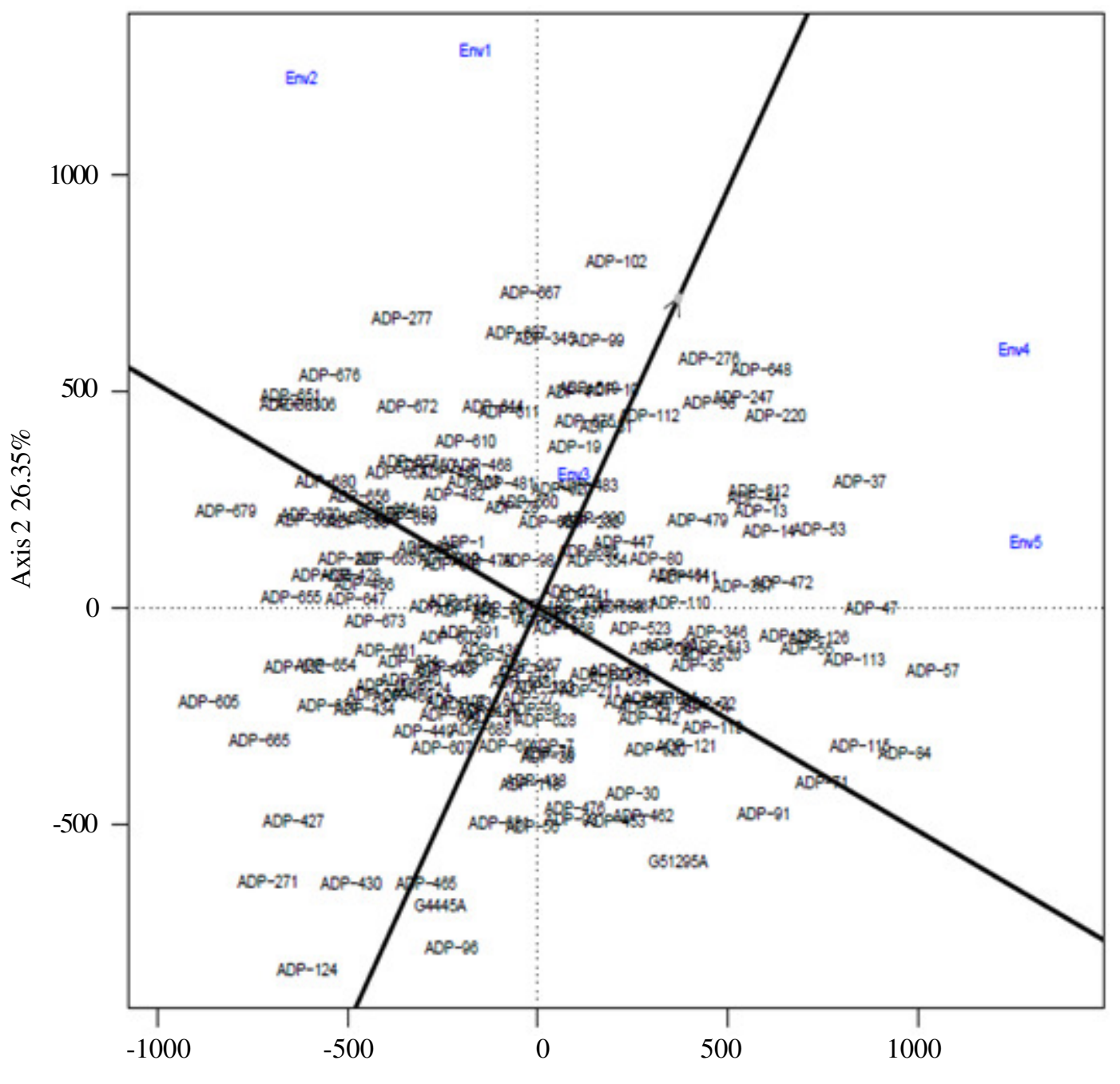

Axis $141.21 \%$

Figure 6. Ranking of the Andean dry bean genotypes relative to ideal genotype for yield performance in five test environments in Tanzania.

with low mean yield, provided that the yield is consistently low across environments. Therefore, stable genotypes are preferred only if they have higher mean yield across environments.

An ideal genotype has high mean yield performance, and higher stability across environments. The arrow inside the blue circle is where an ideal genotype should be. All genotypes located close to where an ideal genotype is, are more desirable. In this case,
ADP-102 was most desirable followed by ADP-276, ADP-667, ADP-99, ADP-684 and the poorest genotype was ADP-124 because it is at the bottom of environmental axis (Fig. 6).

\section{CONCLUSION}

The study revealed significant $\mathrm{G}, \mathrm{E}$ and $\mathrm{GE}$ variance for seed yield in Andean dry bean genotypes tested in different environments in 
Tanzania. The Andean genotypes in this study exhibit a broad range of variation in yield under contrasting environments, which differed for water stress, soil fertility and general climatic conditions.

A few stable high yielding genotypes were found, including ADP-102 (Jessica)- purple mottle, large seed, bush plant habit, released by Selian Agriculture Research Institution (ARI) in Tanzania; ADP-220 (G5625)- red, large seed, vine plant habit from Central America; ADP-276 (G13654) - brown, medium seed, vine, from Mexico; and ADP648 ('Red Kloud') large red kidney, with bush plant habit, from North America. These represent suitable materials for breeding for wide adaptation. The lines which performed well under low fertility and or water stress environments may possess abiotic stress tolerance and may be useful in breeding for improved yield stability for such conditions. An ideal environment was not identified for selecting genotypes with wide adaptation, indicating the continued need to maintain separate breeding and selection programs in the Northern (Arusha) and Southern Highlands (Mbeya) production regions of Tanzania.

Biplot analysis gave a good indication of genotypic performance across environments. An ideal genotype should have higher mean yield than other genotype and an ideal environment should have higher mean yield compared to other environments. GGE analysis can be helpful for making better decisions about which genotypes should be recommended for release in specific environments or across environments.

\section{AKNOWLEDGEMENT}

Funding was provided by the Norman Borlaug Commemorative Research Initiative between US Agency for International Development and the US Department of Agriculture; Agricultural Research Service, through Cooperative Agreement Number 58-0210-3-012 (4085354-012); and from the Feed the Future Innovation Lab for Climate Resilient Beans
Project \# AID-OAA-A-13-00077. The study was supported by the USDA-ARS Prosser WA; Department of Crop and Soil Science, Washington State University; Department of Crop Science and Horticulture, Sokoine University of Agriculture - Tanzania.

\section{REFERENCES}

Beebe, S., Rengifo, J. Gaitan, E. Duque, M.C. and Tohme, J. 2001. diversity and origin of andean landraces of common bean. Crop Science 41:854-862.

Beyene, Y., Mugo, S. Mutinga, C. Tefera, T. Karaya, H. Ajang, S. Shuma, J. Tende, R. and Kega, V. 2011. Genotype by environment interactions and yield stability of stem borer resistant maize hybrids in Kenya. African Journal of Biotechnology 10:4752 - 4758.

Cichy, K.A., Porch, T.G. Beaver, J.S. Cregan, P. Fourie, D. Glahn, R. Grusak, M.A. Kamfwa, K. Katuuramu, D.N. McClean, P. Mndolwa, E.J. Nchimbi-Msolla, S. Pastor-Corrales, M.A. and Miklas, P.N. 2015. A Phaseolus Vulgaris Diversity Panel for Andean Bean Improvement. Crop Science 55:2149-2160.

Clark, R.B. and Duncan, R.R. 1991. Improvement of plant mineral nutrition through breeding. Field Crops Research 27: 219-240.

Frutos, E., Galindo, M.P. and Leiva, V. 2013. An interactive biplot implementation in $\mathrm{R}$ for modeling genotype-by-environment interaction. Stochastic Environmental Research and Risk Assessment 28(7):16291641. DOI 10.1007/s00477-013-0821-z.

Ghassemi, F., Jakeman, A.J. and Nix, H.A. 1995. Salinisation of land and water resources. Wallingford Oxon, UK, CAB International. pp. 1-16.

Kelly, J.D., Kolkman, J.M. and Schneider, K. 1998. Breeding for yield in dry bean (Phaseolus vulgaris L.). Euphytica 102: $343-356$.

Makumbi, D., Diallo, A. Kanampiu, K. Mugo, S. and Karaya, H. 2015. Agronomic 
performance and genotype $\mathrm{x}$ environment interaction of herbicide-resistant maize varieties in Eastern African Crop Science Journal 55:540-555.

Pessarakli, M. and Szabolcs, I. 1999. Soil salinity and sodicity as particular crop stress factors. In: $M$ Pessarakli, ed.handbook of plant and crop stress. 2nd ed. In: M. Pessarakli, editor MarcelDekker., New York, USA. pp. 1-16.

SAS Institute. 2011. SAS Version 9. SAS Institute Inc., Cary, NC., USA.

Singh, S.P. 1999. Production and utilization: In common bean improvement in the twenty-first century. Kluwer Academic Publishers, Dordrecht, NL; Boston, MA, USA.

Sserumaga, J.P., Oikeh, S.O. Mugo, S. Asea, G. Otim, M. Beyene, Y. Abalo, G. and Kikafunda, J. 2015. Genotype by environment interactions and agronomic performance of doubled haploids testcross maize (Zea mays L.) hybrids. Springer, Dordrecht. pp. 353-365.

Vandemark, G.J., Brick, M.A. Osorno, J.M. Kelly, J.D. and Urrea, C.A. 2014. Edible grain legumes. In: Smith, S. et al., (Eds.),
Yield gains in major U.S. field crops. American Society of Agronomy, Inc., Crop Science Society of America, Inc., and Soil Science Society of Amer-ica, Inc., Madison, WI., USA. pp. 87-124.

Van-Eeuwijk, F.A. 1995. Linear and bilinear models for the analysis of multienvironment trials: An application of data from dutch maize variety trials. Euphytica $84: 9-22$.

Villegas, H., Wright, E.M. and Kelly, J.D. 2016. GGE Biplot analyisis of yield associations with root traits in a mesoamerican bean diversity panel. Crop Science 56:10801094.

Wortmann, C.S., Lunze, L. Ochwoh, V.A. and Lynch, J. 1995. Bean improvement for low fertility soils in Africa. African Crop Science Journal 3:469-477.

Yan, W., Hunt, L. Sheng, Q. and Szlavnics, Z. 2000. Cultivar evaluation and megaenvironment investigation based on the GGE biplot. Crop Science 40:597-605.

Yan, W. and Tinker, N.A. 2006. Biplot analysis of multi-environment trial data: Principles and applications. Canadian Journal of Plant Science 86:623-645. 